\title{
Pengembangan Kapasitas Subak CuculanSebagai Wahana Belajar Petani di Desa Pemogan Kecamatan Denpasar Selatan Kota Denpasar
}

\author{
NANDA AGITA SAPUTRI, I GEDE SETIAWAN ADI PUTRA, \\ I MADE SARJANA
}

\author{
Program Studi Agribisnis, Fakultas Pertanian, Universitas Udayana \\ J1.PB. Sudirman, Denpasar 80323 \\ Email: nanda.agita@yahoo.co.id \\ igedesetiawanadiputra@gmail.com
}

\begin{abstract}
The Development of Subak of Cuculan Capacity as a Learning Facility for Farmers in the Pemogan Village, the Sub-District of South Denpasar, Denpasar City
\end{abstract}

Capacity development is the process of building the capacity of individuals, groups, or organizations. Subak is a farmer organization in Bali. The study aimed to describe the capacity of Subak Cuculan as a learning facility for farmers, to describe the function of learning facility of farmers in Subak Cuculan, to analyze the relationship between Subak Cuculan capacity and the function of learning facility of farmers in the Subak Cuculan, and to analyze the development of Subak Cuculan capacity as an effective farmer learning facility. The research location was determined in Pemogan Village purposively by the population of 50 people and the sample was 44 people based on the slovin formula and the data were analyzed by descriptive analysis and rank spearman statistical test. Subak Cuculan capacity is classified as moderate category.The function of the farmers' learning facility in Subak Cuculan is classified in the high category. Capacity of Subak Cuculan and the learning facility function in Subak Cuculan have significant relation of 59\%. Subak Cuculan capacity building efforts can be analyzed in physical and non-physical form by identifying problems, problem formulation, and finding solutions for problem solving. Subak Cuculan members are expected to be more passionate in carrying out their farming and more active in utilizing the learning facility in Subak Cuculan. It is also expected that good cooperation from all related parties, namely Subak Cuculan farmers, the agricultural extension agents in South Denpasar, and the Department of Agriculture and Horticulture of Denpasar City in the development of capacity of Subak Cuculan as a learning facility for the farmers.

Keywords: function of farmers, learning facility, capacity development, subak 


\section{Pendahuluan}

\subsection{Latar Belakang}

Subak Cuculan merupakan salah satu organisasi subak yang tergabung ke dalam Gabungan Kelompok Tani (Gapoktan) Mekar Sari di Desa Pemogan, Kecamatan Denpasar Selatan, Kota Denpasar, yang sejak tahun 2012 telah mendapat binaan dari Dinas Pertanian Tanaman Pangan dan Hortikultura Kota Denpasar dan Petugas Penyuluh Lapangan Denpasar Selatan untuk penerapan sistem tanam jajar legowo. Subak Cuculan merupakan salah satu subak berprestasi di Kota Denpasar, karena pada tahun 2007 Subak Cuculan telah berhasil meraih juara satu tingkat Provinsi Bali dalam kategori penerapan teknologi. Subak Cuculan juga unggul dalam produktivitas karena jumlah produktivitas padi di Subak Cuculan sebesar 10,35 ton/ha yang mampu melebihi rata-rata jumlah produktivitas nasional yaitu sebesar 8,5 ton/ha.

Subak Cuculan memiliki kapasitas yang dapat dilihat dalam konteks sosial, ekonomi, maupun lingkungan. Permasalahan lingkungan yang ada pada Subak Cuculan yaitu terjadinya alih fungsi lahan. Pada tahun 1950 Subak Cuculan memiliki luas lahan 250 ha dan saat ini pada tahun 2017 luas lahan Subak Cuculan adalah 77 ha(Balai Penyuluhan Pertanian Denpasar Selatan, 2015).

Pengembangan kapasitas merupakan proses membangun kapasitas individu, kelompok, atau organisasi. Peneliti tertarik melakukan analisis pengembangan kapasitas Subak Cuculan sebagai wahana belajar petani sebab kapasitas Subak Cuculan yang ada saat ini belum berkembang, sedangkan Subak Cuculan telah memenuhi syarat sebagai wahana belajar petani, sehingga hasil akhir dari penelitian ini dapat memberikan solusi untuk pengembangan kapasitas Subak Cuculan sebagai wahana belajar petani.

\subsection{Tujuan}

Berdasarkan latar belakang masalah tersebut di atas, maka dapat dirumuskan masalah penelitian sebagai berikut.

1. Mendeskripsikan kapasitas Subak Cuculan sebagai wahana belajar petani.

2. Mendeskripsikan fungsi wahana belajar pada Subak Cuculan.

3. Menganalisis hubungan antara kapasitas Subak Cuculan dan fungsi wahana belajar petani pada Subak Cuculan.

4. Menganalisis pengembangan kapasitas Subak Cuculan sebagai wahana belajar petani yang efektif dan efisien.

\section{Metode Penelitian}

\subsection{Lokasi dan Waktu Penelitian}

Lokasi penelitian ini dilakukan di Desa Pemogan, Kecamatan Denpasar Selatan, Kota Denpasar pada bulan November 2016 sampai Januari 2017. Pemilihan lokasi penelitian dilakukan secara sengaja berdasarkan pertimbangan yaitu (1) Subak Cuculan merupakan salah satu subak berprestasi di Kota Denpasar, (2) Subak 
Cuculan memiliki potensi yang besar untuk dikembangkan sebagai wahana belajar petani, dan (3) Belum ada penelitian di Subak Cuculan mengenai pengembangan kapasitas Subak Cuculan sebagai wahana belajar petani.

\subsection{Jenis Data dan Sumber Data}

Data yang dikumpulkan dalam penelitian ini adalah data kualitatif dan data kuantitatif, sedangkan sumber data terdiri dari data primer dan data sekunder.

\subsection{Metode Pengumpulan Data}

Metode yang diperlukan dalam penelitian ini dikumpulkan dengan menggunakan teknik wawancara, wawancara mendalam, dan observasi.

\subsection{Responden Penelitian}

Populasi dalam penelitian ini adalah anggota kelompok Subak Cuculan yang telah diberikan beberapa kali penyuluhan tentang sistem tanam jajar legowo yang berjumlah 50 orang.Jumlah responden sebanyak 44 orang diperoleh dari perhitungan dengan menggunakan rumus slovin. Metode yang digunakan ialah simple random sampling.

\subsection{Variabel dan Metode Analisis}

Variabel yang diukur dalam analisis ini adalah karakteristik petani $\left(\mathrm{X}_{1}\right)$ yang terdiri dari: umur, pengalaman berusahatani, pendidikan formal, pendidikan nonformal, jumlah tanggungan rumah tangga, dan luas lahan. Potensi petani $\left(\mathrm{X}_{2}\right)$ yang terdiri dari: lahan pertanian, air, uang, alsintan, kepercayaan, norma, dan jaringan. Fungsi wahana belajar petani (Y) yang terdiri dari: media informasi, media inovasi, dan media pemecahan masalah. Ketiga variabel tersebut diukur dengan menggunakan skala ordinal. Skor yang diberikan yaitu 1, 2, 3, 4, dan 5. Skor 1 menyatakan sangat rendah, skor 2 menyatakan rendah, skor 3 menyatakan sedang, skor 4 menyatakan tinggi, dan skor 5 menyatakan sangat tinggi. Data yang telah dikumpulkan dianalisis melalui pendekatan analaisis deskriptif dan analisis korelasi rank spearman.

\section{Hasil dan Pembahasan}

\subsection{Karakteristik Responden}

Karakteristik responden di Subak Cuculan diperoleh dari data umur, pengalaman berusahatani, pendidikan formal, pendidikan nonformal, jumlah tanggungan rumah tangga, dan luas lahan. 
Tabel 1.

Distribusi Responden Berdasarkan Karakteristik di Subak Cuculan, Tahun 2017

\begin{tabular}{cllcc}
\hline No & \multicolumn{1}{c}{ Karakteristik Petani } & \multicolumn{1}{c}{ Kategori } & $\begin{array}{c}\text { Jumlah } \\
\text { (orang) }\end{array}$ & \multicolumn{1}{c}{$\%$} \\
\hline$(1)$ & \multicolumn{1}{c}{$(2)$} & \multicolumn{1}{c}{$(3)$} & $(4)$ & $(5)$ \\
\hline 1 & Umur & Sedang (59-66 th) & 20 & 45,5 \\
2 & Pengalaman berusahatani & Sedang (44-51 th) & 20 & 45,5 \\
3 & Pendidikan formal & Sangat rendah (6-8 th) & 39 & 88,6 \\
4 & Pendidikan nonformal & Rendah (5,8-8,4 kali) & 21 & 52,3 \\
5 & Jumlah tanggungan rumah tangga & Sedang (4,6-5,4 orang) & 23 & 52,3 \\
6 & Luas lahan & Sangat sempit (50-120 are) & 14 & 31,8 \\
\hline \multicolumn{2}{l}{ Sumber : Analisis data primer, 2017 } & & &
\end{tabular}

Sumber : Analisis data primer, 2017

Berdasarkan Tabel 1 umur responden di Subak Cuculan tergolong dalam kategori produktif yang menunjukkan bahwa kemampuan belajar responden masih cukup baik untuk menerima informasi pertanian dalam rangka meningkatkan kapasitasnya.Hasil penelitian ini sejalan dengan Sudartana (2016), yang menyatakan bahwa penduduk dengan umur produktif memiliki daya serap terhadap inovasi yang semakin baik, sebab penduduk dengan umur produktif memiliki semangat yang tinggi untuk mencoba sesuatu serta mampu memanfaatkan sumber daya dan fasilitas yang tersedia.

Pengalaman berusahatani responden sudah cukup lama sehingga mampu meningkatkan kompetensi responden untuk memanfaatkan wahana belajar, seperti saling bertukar informasi pertanian berdasarkan pengalaman mereka. Hasil penelitian ini sejalan dengan Padmowiharjo (1999), yang menyatakan bahwa pengalaman berusahatani memegang peranan penting dalam peningkatan kompetensi petani di dalam proses belajar.

Tingkat pendidikan formal responden yang sangat rendah menjadi latar belakang pengembangan wahana belajar petani pada Subak Cuculan dengan tujuan untuk meningkatkan pengetahuan, sikap, dan keterampilan petani dalam proses belajar dan mengelola usahatani.Hasil penelitian ini sejalan dengan Saridewi (2010), yang menyatakan bahwa tingkat pendidikan seseorang dapat mengubah pengetahuan, sikap, dan keterampilan yang lebih baik, serta mendukung proses belajar di kemudian hari.

Tingkat partisipasi responden dalam mengikuti pendidikan nonformal masih rendah, oleh sebab itu untuk melakukan pengembangan kapasitas Subak Cuculan sebagai wahana belajar petani perlu dibuatkan suatu program pendidikan nonformal yang dapat menarik minat responden.Partisipasi anggota yang baik akan mendukung keberhasilan pembelajaran di Subak Cuculan. Hasil penelitian ini sejalan dengan Yamin (2007), yang menyatakan bahwa partispasi siswa belajar merupakan hal yang sangat penting untuk menentukan keberhasilan pembelajaran.

Jumlah tanggungan rumah tangga yang dimiliki responden cukup menjadi motivasi bagi responden untuk lebih giat belajar dan berproduksi supaya dapat meningkatkan taraf hidup dan memenuhi kebutuhan rumah tangga.Motivasi tersebut 
juga turut mendorong anggota dalam memanfaatkan fungsi wahana belajar di Subak Cuculan.Hasil penelitian ini sejalan dengan Arimbawa (2004) yang menyatakan bahwa jumlah tanggungan rumah tangga menjadi motivasi untuk lebih giat lagi dalam berproduksi dan melakukan proses belajar.

Sebagian besar responden di Subak Cuculan merupakan petani lahan sempit.Kondisi luas lahan yang sempit memberikan pendapatan yang sedikit pula, akibatnya petani menjadi kurang bersemangat dalam berusahatani dan mengadopsi inovasi.Hasil penelitian ini sejalan dengan Hernanto (1993), yang menyebutkan bahwa luas lahan usahatani menentukan pendapatan, taraf hidup, dan derajat kesejahteraan rumah tangga petani, serta menjadi motivasi bagi petani untuk lebih giat dalam berusahatani dan mengadopsi inovasi.

\subsection{Potensi Responden}

Potensi responden merupakan seluruh sumber daya alam maupun sumber daya manusia yang dimiliki responden dan dapat dikembangkan menjadi suatu wahana belajar petani di Subak Cuculan.Potensi responden di Subak Cuculan diperoleh dari data tingkat kesuburan lahan pertanian, air, uang, alsintan, kepercayaan, norma, dan jaringan.

Tabel 2.

Distribusi Responden Berdasarkan Potensi di Subak Cuculan, Tahun 2017

\begin{tabular}{cllcc}
\hline No & \multicolumn{1}{c}{ Indikator } & Kategori & $\begin{array}{c}\text { Jumlah } \\
\text { (orang) }\end{array}$ & $\%$ \\
\hline$(1)$ & \multicolumn{1}{c}{$(2)$} & \multicolumn{1}{c}{$(3)$} & $(4)$ & $(5)$ \\
\hline 1 & Tingkat kesuburan lahan pertanian & Baik & 26 & 59,1 \\
2 & Ketersediaan air irigasi & Baik & 35 & 79,5 \\
3 & Kualitas air irigasi & Baik & 35 & 79,5 \\
4 & Kontinuitas air irigasi & Baik & 35 & 79,5 \\
5 & Ketersediaan uang & Sedang & 21 & 47,7 \\
6 & Kemudahan mendapatkan uang & Baik & 30 & 68,2 \\
7 & Alsintan & Sangat sedikit $(4-4,6$ unit) & 31 & 70,5 \\
6 & Kepercayaan kepada pengurus & Baik & 29 & 65,9 \\
7 & Kepercayaan kepada sesama anggota & Baik & 29 & 65,9 \\
8 & Kepercayaan kepada orang lain & Tidak baik & 40 & 90,9 \\
9 & Awig-awig & Baik & 37 & 84,1 \\
10 & Pararem & Baik & 37 & 84,1 \\
11 & Jaringan local & Tidak baik & 42 & 95,5 \\
12 & Jaringan nasional & Sangat tidak baik & 40 & 90,9 \\
13 & Jaringan internasional & Sangat tidak baik & 40 & 90,9 \\
\hline Sumber $:$ Analisis data primer, 2017 & & &
\end{tabular}

Berdasarkan Tabel2 menunjukkan bahwa tingkat kesuburan lahan pertanian, ketersediaan, kualitas, dan kontinuitas air irigasi, ketersediaan dan kemudahan mendapatkan modal finansial (uang), kepercayaan kepada pengurus dan sesama anggota, awig-awig, dan pararem yang ada di Subak Cuculan tergolong pada kategori baik sehingga seluruh potensi tersebut mampu mendukung berjalannya 
fungsi wahana belajar petani di Subak Cuculan. Kepercayaan kepada orang/kelompok/instansi di luar Subak Cuculan dan jaringan dalam skala lokal berada dalam kategori tidak baik dan jaringan dalam skala nasional dan internasional berada pada kategori sangat tidak baik sehingga hal ini menghambat fungsi Subak Cuculan sebagai wahana belajar petani. Kepercayaan dan jaringan di Subak Cuculan harus diperbaiki lagi sehingga akan terjalin kerjasama yang baik antara Subak Cuculan dengan pihak luar dalam memperoleh informasi pertanian, memperoleh sumber daya, pengelolaan pra dan pasca panen, serta pemasaran. Hasil penelitian ini sejalan dengan Damsar (2002) yang menyatakan bahwa jaringan memiliki fungsi sebagai hubungan antara individu yang akan memfasilitasi terjadinya komunikasi atau interaksi, sehingga dengan terjadinya komunikasi atau interaksi secara kontinyu memungkinkan tumbuhnya sikap saling percaya satu sama lain dan memperkuat kerjasama dalam memperoleh informasi pertanian, memperoleh sumberdaya, pengelolaan pra dan pasca panen, dan pemasaran.

\subsection{Fungsi Wahana Belajar Petani di Subak Cuculan}

Fungsi wahana belajar petani di Subak Cuculan dapat dilihat dari data fungsi Subak Cuculan sebagai media informasi, media inovasi, dan media pemecahan masalah.

Tabel 3.

Distribusi Responden Berdasarkan Fungsi Wahana Belajar Petani di Subak Cuculan, Tahun 2017

\begin{tabular}{|c|c|c|c|c|c|}
\hline No & $\begin{array}{c}\text { Fungsi wahana belajar } \\
\text { petani }\end{array}$ & Indikator & Kategori & $\begin{array}{l}\text { Jumlah } \\
\text { (orang) }\end{array}$ & $\%$ \\
\hline (1) & $(2)$ & (3) & (4) & (5) & (6) \\
\hline \multirow[t]{4}{*}{1} & \multirow[t]{4}{*}{ Media informasi } & Aktual & Baik & 32 & 72,7 \\
\hline & & Cepat & Baik & 33 & 75 \\
\hline & & Mudah & Bak & 42 & 95,5 \\
\hline & & Murah & Baik & 42 & 95,5 \\
\hline \multirow[t]{4}{*}{2} & \multirow[t]{4}{*}{ Media inovasi } & Observability & Baik & 36 & 81,8 \\
\hline & & Triability & Baik & 36 & 81,8 \\
\hline & & Complexity & Sedang & 42 & 95,5 \\
\hline & & Compatibility & Sedang & 42 & 95,5 \\
\hline \multirow[t]{7}{*}{3} & \multirow{7}{*}{$\begin{array}{l}\text { Media pemecahan } \\
\text { masalah }\end{array}$} & Relative advantage & Baik & 43 & 97,7 \\
\hline & & Identifikasi masalah & Baik & 32 & 72,7 \\
\hline & & Perumusan masalah & Baik & 32 & 72,7 \\
\hline & & Perancangan alternatif & Baik & 32 & 72,7 \\
\hline & & Pemecahan masalah & Baik & 37 & 84,1 \\
\hline & & Evaluasi solusi & Baik & 30 & 68,2 \\
\hline & & $\begin{array}{l}\text { Implementasi solus } \\
\text { terbaik }\end{array}$ & Baik & 39 & 88,6 \\
\hline
\end{tabular}

Sumber : Analisis data primer, 2017

Berdasarkan Tabel 3 Subak Cuculan sebagai wahana belajar petani telah mampu menjadi media informasi bagi anggotanya dengan aktual, cepat, mudah, dan murah. Fungsi media informasi yang dijalankan dengan baik mendukung Subak 
Cuculan sebagai wahana belajar petani. Media informasi tersebut dapat dikembangkan dengan memperkenalkan petani terhadap media informasi yang lebih maju, sehingga penyebaran informasi di kalangan petani Subak Cuculan dapat berlangsung dengan lebih aktual, cepat, mudah, dan murah. Hasil penelitian ini sejalan dengan Andriaty dan Setyorini (2012), yang menyatakan bahwa untuk mempercepat penyampaian informasi teknologi pertanian dapat dilakukan dengan mengubah paradigma diseminasi dari yang bersifat konvensional ke arah yang lebih maju dan cepat dengan memanfaatkan berbagai saluran atau media.

Subak Cuculan sebagai wahana belajar petani khususnya dalam pemanfaatan media inovasi sistem tanam jajar legowo sudah mampu diamati dan dicoba oleh responden, namun responden masih menemukan kerumitan, kendala, dan tidak mendapatkan keuntungan ekonomi, meskipun sistem tanam jajar legowo telah terbukti dapat meningkatkan produktivitas.Media inovasi di Subak Cuculan masih perlu dikembangkan untuk mendukung proses belajar petani. Media inovasi Subak Cuculan sebagai wahana belajar petani dapat dikembangkan dengan cara memberikan atau menciptakan suatu inovasi yang sesuai dengan kebutuhan Subak Cuculan, inovasi yang mampu mengatasi permasalahan yang terjadi, dan inovasi yang bersifat mudah diamati, mudah dicoba, tidak rumit, sesuai untuk diterapkan baik secara ekonomi, lingkungan, maupun sosial budaya, serta dapat memberikan keuntungan relatif. Hasil penelitian ini sejalan dengan Rogers (1983) yang mengemukakan lima karakteristik inovasi yang dapat memengaruhi keputusan terhadap pengadopsian suatu inovasi: observability (mudah diamati), triability (mudah dicoba), complexity (tidak rumit), compatibility (sesuai), dan relative advantage (meberikan keuntungan relatif).

Subak Cuculan telah menjalankan fungsinya sebagai media pemecahan masalah dengan baik. Seluruh tahapan pemecahan masalah dilakukan bersama-sama oleh pengurus dan anggota Subak Cuculan melalui musyawarah. Setiap keputusan yang diambil oleh ketua berdasarkan kesepakatan seluruh anggota Subak Cuculan.Media pemecahan masalah perlu dikembangkan dengan melibatkan pihak yang berkompeten sehingga dapat memaksimalkan hasil dari pemanfaatan wahana belajar di Subak Cuculan sebagai media pemecahan masalah.

\subsection{Hubungan Kapasitas Subak Cuculan dengan Fungsi Wahana Belajar Petani di Subak Cuculan}

Hubungan kapasitas Subak cuculan dengan fungsi wahana belajar petani di Subak Cuculan dapat dianalisis dengan menghubungkan variabel kapasitas Subak Cuculan dengan variabel fungsi wahana belajar petani yang terdiri dari media informasi, media inovasi, dan media pemecahan masalah. 


\section{Tabel 4.}

Analisis Hubungan Kapasitas Subak Cuculan dengan Wahana Belajar Petani di Subak Cuculan, Tahun 2017

\begin{tabular}{clrrr}
\hline \multirow{2}{*}{ No } & \multicolumn{1}{c}{ Kapasitas Subak Cuculan } & \multicolumn{2}{c}{ Fungsi Wahana belajar Petani } \\
\cline { 3 - 5 } & & $\begin{array}{c}\text { Media } \\
\text { Informasi }\end{array}$ & $\begin{array}{c}\text { Media } \\
\text { Inovasi }\end{array}$ & $\begin{array}{c}\text { Media } \\
\text { Pemecahan } \\
\text { Masalah }\end{array}$ \\
\hline \multicolumn{1}{c}{$(2)$} & & \multicolumn{1}{c}{$(3)$} & \multicolumn{1}{c}{$(5)$} \\
\hline 1 & Umur & $0,361^{*}$ & 0,037 & 0,177 \\
2 & Pengalaman berusahatani & $0,361^{*}$ & 0,038 & 0,178 \\
3 & Pendidikan formal & $0,450^{* *}$ & 0,296 & $0,327^{*}$ \\
4 & Pendidikan nonformal & $0,666^{* *}$ & $0,365^{*}$ & $0,416^{* *}$ \\
5 & Jumlah tanggungan rumah tangga & 0,277 & 0,000 & 0,150 \\
6 & Luas lahan & 0,232 & $0,367^{*}$ & $0,336^{*}$ \\
7 & Lahan pertanian & 0,160 & 0,262 & $0,447^{* *}$ \\
8 & Air & $0,488^{* *}$ & $0,430^{* *}$ & 0,199 \\
9 & Uang & $0,484^{* *}$ & $0,423^{* *}$ & 0,135 \\
10 & Alsintan & $0,353^{*}$ & $0,440^{* *}$ & 0,203 \\
11 & Kepercayaan & 0,264 & $0,699^{* *}$ & $0,368^{*}$ \\
12 & Norma & $0,753^{* *}$ & $0,502^{* *}$ & 0,242 \\
13 & Jaringan & $0,455^{* *}$ & $0,609^{* *}$ & $0,492^{* *}$ \\
\hline
\end{tabular}

Sumber : Analisis data primer, 2017

Keterangan: $(*) \quad=$ Correlation is significant at the 0.05 level (2-tailed) $(* *)=$ Correlation is significant at the 0.01 level (2-tailed)

Berdasarkan Tabel 4 diketahui bahwa pendidikan nonformal berhubungan sangat signifikan $\left(0,666^{* *}\right)$ dengan fungsi wahana belajar Subak Cuculan sebagai media informasi. Artinya, pendidikan nonformal yang pernah diikuti anggota dalam kategori rendah berhubungan dengansikap anggota dalam bertukar informasi pertanian yang belum maksimal karena rendahnya pengetahuan dan banyak bias.

Modal kepercayaan berhubungan sangat signifikan $(0,699 * *)$ dengan fungsi Subak Cuculan sebagai media inovasi.Artinya, rendahnya tingkat kepercayaan yang terjalin antara anggota dengan instansi lain di luar Subak Cuculan (Dinas Pertanian dan Hortikultura Kota Denpasar dan PPL Denpasar Selatan) berhubungan dengan penolakan inovasi sitem tanam jajar legowo di Subak Cuculan.

Norma berhubungan sangat signifikan $\left(0,753^{* *}\right)$ dengan fungsi Subak Cuculan sebagai media informasi. Artinya, norma yang ditaati oleh anggota dengan kategori baik berhubungan dengan sikap tertib anggota dalam penyebaran informasi sistem tanam jajar legowo.Tata cara penyampaian informasi pada Subak Cuculan telah diatur di dalam pararem Subak Cuculan, yakni informasi yang didapat oleh Pekaseh akan disampaikan kepada masing-masing Pengliman, kemudian Pengliman bertugas menyampaikan informasi tersebut kepada masing-masing anggota, dengan demikian penyebaran informasi di Subak Cuculan dapat berjalan dengan actual, cepat, mudah, dan murah.

Norma berhubungan sangat signifikan $(0,502 * *)$ dengan fungsi Subak Cuculan sebagai media inovasi.Artinya, norma yang ditaati oleh anggota dengan kategori baik berhubungan dengan sikap tertib anggota dalam penyebaran dan penolakan inovasi 
sistem tanam jajar legowo.Inovasi sistem tanam jajar legowo yang dirasa tidak dapat memberikan keuntungan ekonomimenyebabkan inovasi tersebut tidak diadopsi olehanggota Subak Cuculan.

Jaringan berhubungan sangat signifikan $\left(0,455^{* *}, 0,609 * *\right.$, dan $\left.0,492^{* *}\right)$ dengan fungsi Subak Cuculan sebagai media informasi, media inovasi, dan media pemecahan masalah. Artinya, jaringan yang tergolong dalam kategori rendah berhubungan dengan keterbatasan pengetahuan anggota dan mengalami banyak masalah dalam memanfaatkan media informasi, media inovasi, dan media pemecahan masalah.Hal ini dikarenakantidak adanya hubungan kerjasama dengan pihak lainsehingga menyebabkan anggota Subak Cuculan terbatas dalam mendapatkan informasi dan inovasi pertanian, serta kesulitandalam mengatasi permasalahan yang ada.

\subsection{Pengembangan Kapasitas Subak Cuculan Sebagai Wahana Belajar Petani}

Upaya pengembangan kapasitas Subak Cuculan sebagai wahana belajar petani dapat dirumuskan melalui identifikasi masalah, perumusan masalah, dan pencarian solusi untuk pemecahan masalah tersebut. Upaya tersebut dapat diusulkan dalam bentuk fisik maupun nonfisik dan dijelaskan sebagai berikut.

1. Pemberian program pendidikan nonformal dengan konsep pendidikan orang dewasa dan farmer led extention, yakni proses pembelajaran dengan membangun proses komunikasi multiarah antara penyuluh dengan petani yang melibatkan sharing, pengembangan pengetahuan dan keterampilan, dan mengembangkan kapasitas inovatif di antara semua pelaku. Petani agar lebih dilibatkan lagi dalam penyelesaian masalah dan diposisikan sebagai pelaku utama dalam proses belajar. Proses pembelajaran dapat diciptakan dalam bentuk eksperimen, diskusi, pemecahan masalah, latihan, simulasi, dan praktek lapangan.

2. Pelibatan anggota muda dalam proses pembelajaran, pengelolaan usahatani, dan pengembangan organisasi. Pelibatan anggota muda diharapkan dapat membuat anggota muda ikut berpikir atas permasalahan yang sedang dihadapi dan dapat ikut berkontribusi dalam pengembangan Subak Cuculan.

3. Pembuatan lahan khusus untuk tempat percobaan petani dan mempelajari inovasi baru.

4. Pengembangan modal sosial di Subak Cuculan, yaitu dengan meningkatkan kepercayaan anggota Subak Cuculan terhadap orang/kelompok/instansi lain di luar Subak Cuculan. Orang/kelompok/instansi di luar Subak Cuculan dapat berupa, seseorang atau kelompok tani yang telah sukses dalam berusahatani, ilmuwan, lembaga akademis, Dinas Pertanian Tanaman Pangan dan Hortikultura Kota Denpasar, Petugas Penyuluh Lapangan Denpasar Selatan, dan LSM. Pengembangan modal sosial juga dapat dilakukan dengan membangun jaringan dalam skala lokal terlebih dahulu, selanjutnya diperluas dalam skala nasional dan internasional. Subak Cuculan dapat membangun jaringan dan kerjasama 
dengan pihak lain untuk mencari informasi pertanian, memperoleh sumber daya, pengelolaan pra dan pasca panen, serta pemasaran.

\section{Simpulan dan Saran}

\subsection{Simpulan}

Hasil penelitian ini dapat disimpulkan bahwa kapasitas Subak Cuculan tergolong dalam kategori sedang. Fungsi wahana belajar petani pada Subak Cuculan tergolong dalam kategori tinggi. Kapasitas Subak Cuculan dan fungsi wahana belajar petani di Subak Cuculan terdapat hubungan yang signifikan dengan persentase sebesar 59\%. Upaya pengembangan kapasitas Subak Cuculan dapat dianalisis dalam bentuk fisik maupun nonfisik dengan melakukan identifikasi masalah, perumusan masalah, dan pencarian solusi untuk pemecahan masalah.

\subsection{Saran}

Berdasarkan hasil penelitian ini diharapkan agar anggota Subak Cuculan dapat lebih bersemangat dalam menjalankan usahataninya dan lebih aktif dalam memanfaatkan wahana belajar. Penulis juga berharap adanya peran aktif dan kerjasama yang baik dari seluruh pihak yang terkait, yakni petani Subak Cuculan, pemuda-pemudi Desa Pemogan, pemilik lahan, seluruh masyarakat Desa Pemogan, BABINSA Desa Pemogan, PPL Denpasar Selatan, Dinas Pertanian Tanaman Pangan dan Hortikultura Kota Denpasar, danPemerintah Daerah Kota Denpasar dalam pengembangan kapasitas Subak Cuculan sebagai wahana belajar petani.

\section{Ucapan Terimakasih}

Terimakasih kepada Ketua Subak Cuculandan seluruh responden Subak Cuculan yang telah memberikan informasi dan segala bentuk bantuan dalam pelaksanaan penelitian.

\section{Daftar Pustaka}

Andriaty, Etty dan Setyorini Endang. 2012. Ketersediaan Sumber Informasi Teknologi Pertanian di Beberapa Kabupaten di Jawa. Bogor: Pusat Perpustakaan dan Penyebaran Teknologi Pertanian. Tersedia: http://www.ejurnal.litbang.pertanian.go.id/index.php/jpp/article/viewFile/493/p df. Diunduh pada tanggal 1 November 2016.

Arimbawa, P. 2004. Peran Kelompok Untuk Meningkatkan Kemampuan Anggota dalam Penerapan Inovasi Teknologi. Bogor: Institut Pertanian Bogor.

Balai Penyuluhan Pertanian Denpasar Selatan. 2015. Laporan Produsi Tanaman Padi Subak Cuculan Denpasar Selatan. Denpasar

Damsar. 2002. Sosiologi Ekonomi. Jakarta: Raja Grafindo Persada.

Hernanto, F. 1993. Ilmu Usahatani. Penebar Swadaya: Jakarta.

Padmowiharjo. 1999. Evaluasi Penyuluhan Pertanian. Universitas Terbuka: Jakarta.

Rogers. 1983. Media For Interactive Communication. Beverly Hill/Londen/New Delhi: Sage Publications. 
Saridewi. 2010. Pengaruh Profesionalisme, Tingkat Pendidikan, dan Pengalaman Kerja Pada Kinerja Badan Pengawas Lembaga Perkreditan Desa (Penelitian LPD di Kota Denpasar). Denpasar: Universitas Udayana.

Sudartana, Wayan. 2016. Proses Pengadopsian System of Rice Intensification (SRI) oleh Anggota Subak Pacung di Desa Selat, Kecamatan Abiansemal, Kabupaten Badung. Denpasar.

Yamin, Martinis. 2007. Profesionalisasi Guru \& Implementasi KTSP. Jakarta: Gaung Persada Press. 